\title{
Research
}

\section{ERK1/2 Activation Is Necessary for BDNF to Increase Dendritic Spine Density in Hippocampal CAl Pyramidal Neurons}

\author{
Mariana Alonso, ${ }^{1,2}$ Jorge H. Medina, ${ }^{1}$ and Lucas Pozzo-Miller ${ }^{2,3}$ \\ ${ }^{1}$ Instituto de Biología Celular y Neurociencias, Facultad de Medicina, Universidad de Buenos Aires, 1121 Buenos Aires, Argentina; \\ ${ }^{2}$ Department of Neurobiology and Civitan International Research Center, University of Alabama at Birmingham, \\ Birmingham, Alabama 35294, USA
}

\begin{abstract}
Brain-derived neurotrophic factor (BDNF) is a potent modulator of synaptic transmission and plasticity in the CNS, acting both pre- and postsynaptically. We demonstrated recently that BDNF/TrkB signaling increases dendritic spine density in hippocampal CAl pyramidal neurons. Here, we tested whether activation of the prominent ERK (MAPK) signaling pathway was responsible for BDNF's effects on spine growth. Slice cultures were transfected with enhanced yellow fluorescent protein (eYFP) by particle-mediated gene transfer, and CAl pyramidal neurons were imaged by laser-scanning confocal microscopy. We confirmed that BDNF (24 h) increases spine density in apical dendrites of CA1 neurons. The MEK (ERK kinase) inhibitors PD98059 and U0126 completely prevented the increase in spine density induced by BDNF, without having an effect on spine density by themselves. In contrast to its actions on cortical pyramidal neurons, BDNF had minor and rather localized effects on dendritic complexity in hippocampal pyramidal neurons, increasing the total length, but not the branching of apical dendrites within CAl stratum radiatum, without affecting basal dendrites in stratum oriens. Our results support the hypothesis that the ERK-signaling pathway not only mediates long-term synaptic plasticity and hippocampal-dependent learning, but it is also involved in the structural remodeling of excitatory spine synapses triggered by neurotrophins.
\end{abstract}

Due to their effects on synaptic transmission and plasticity (for review, see Poo 2001; Tyler et al. 2002a,b; Vicario-Abejon et al. 2002), neurotrophins in general, and brain-derived neurotrophic factor (BDNF) in particular, are strong candidates to mediate activity-dependent modulation of dendritic structure. BDNF/TrkB signaling modulates dendritic complexity in cortical and cerebellar neurons (McAllister et al. 1995; Schwartz et al. 1997; Shimada et al. 1998; Mertz et al. 2000; Yacoubian and Lo 2000), as well as in dentate granule neurons (Danzer et al. 2002; Tolwani et al. 2002). Overexpression of BDNF in cortical pyramidal neurons caused a destabilization of dendritic spines, suggesting that local dendritic instability allows activity-dependent morphological changes in spine growth to occur (Horch et al. 1999). We demonstrated recently that long-term exposure to BDNF increases apical dendritic spine density in hippocampal CA1 pyramidal neurons (Tyler and Pozzo-Miller 2001, 2003). Despite the potential relevance of these actions for activity-dependent synaptic plasticity and hippocampal-dependent learning and memory, the intracellular signaling pathways responsible for the effects of BDNF on dendritic structure are largely unknown.

The extracellular signal-regulated protein kinase (ERK) signaling pathway could, in principle, mediate the structural changes triggered by BDNF activation of TrkB receptors (for review, see Segal and Greenberg 1996). ERK1/2 signaling mediates the effects of BDNF on synaptic plasticity, nuclear signaling, and memory formation (Finkbeiner et al. 1997; Gottschalk et al. 1999; Blanquet 2000; Pizzorusso et al. 2000; Alonso et al. 2002a,b). In fact, Wu et al. (2001) described that ERK1/2 activation by patterned stimuli was critical for the formation of persis-

\footnotetext{
${ }^{3}$ Corresponding author.
}

E-MAIL pozzomiller@nrc.uab.edu; FAX (205) 934-6571.

Article and publication are at http://www.learnmem.org/cgi/doi/10.1101/ Im.67804. tant dendritic filopodial extensions, their stability being dependent on the stimuli arriving in a spaced, repeated fashion. In an intriguing relationship, this same pattern of stimuli has long been known to fully activate nuclear signaling via cAMP response element-binding protein (CREB), a mechanism implicated in long-term changes in synaptic strength and memory formation (for review, see Lonze and Ginty 2002). We show here that ERK1/2 signaling is also necessary for BDNF to increase spine density in hippocampal CA1 pyramidal neurons.

\section{RESULTS}

BDNF Increases Spine Density in CAl

Pyramidal Neurons

Recently, we demonstrated that BDNF increased spine density in the apical dendrites of CA1 pyramidal neurons using a patchand-fill approach with a fluorescent dye (Alexa-594; Tyler and Pozzo-Miller 2001, 2003). To obtain a higher yield of fluorescently labeled neurons, we transfected hippocampal slice cultures with eYFP using particle-mediated gene transfer (Lo et al. 1994). Transfected slice cultures preserved normal hippocampal cytoarchitecture for at least $12 \mathrm{~d}$ in vitro (div; Fig. 1A). In addition, eYFP-expressing CA1 pyramidal neurons displayed spontaneous excitatory synaptic currents, and fired accommodating trains of evoked action potentials (Fig. 1C-E), thus demonstrating that eYFP biolistic transfection did not cause any detectable deleterious effects on neuronal and synaptic function.

Consistent with our previous observations, application of BDNF $(250 \mathrm{ng} / \mathrm{mL})$ in serum-free medium for $24 \mathrm{~h}$ in vitro increased spine density in secondary and tertiary branches of apical dendrites of eYFP-transfected CA1 pyramidal neurons $(\mathrm{BDNF}=11.17 \pm 0.93$ spines per $10 \mu \mathrm{m}$ of dendritic length, 10 cells from seven slices, vs. serum free $=6.13 \pm 0.62$ spines $/ 10$ 


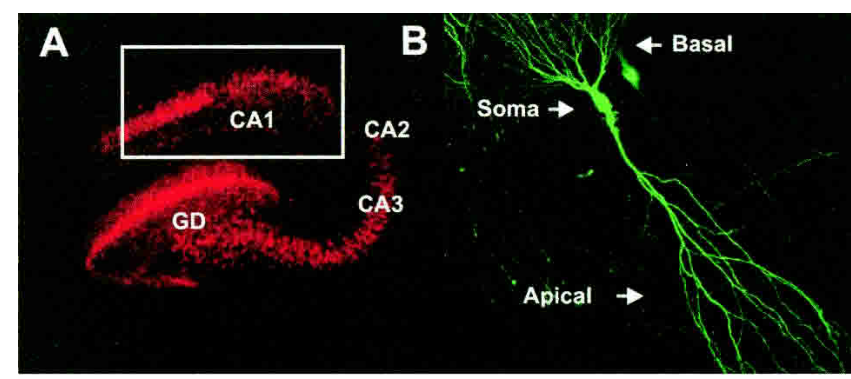

\section{C}

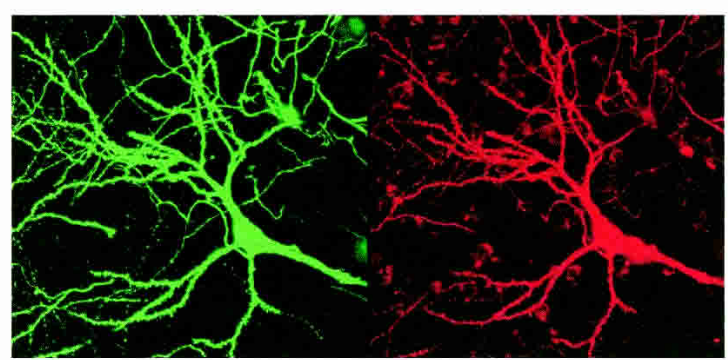

D

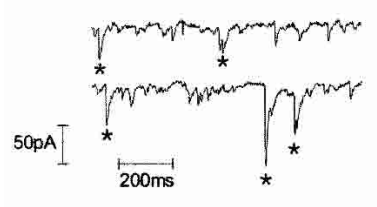

$\mathbf{F}$
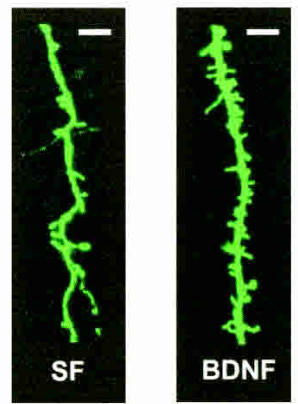

$\mathbf{E}$

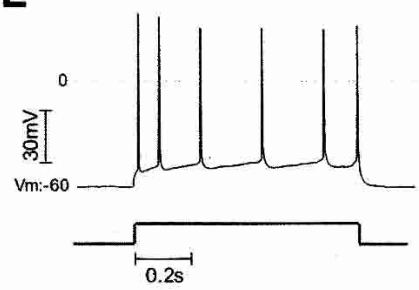

G

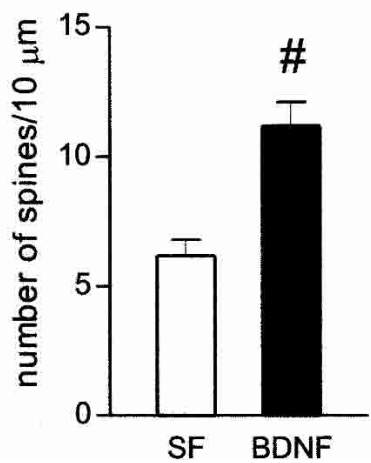

Figure 1 BDNF increases spine density in eYFP-transfected CA1 pyramidal neurons. (A) NeuN immunocytochemistry allowed identification of all hippocampal subfields, CA1, CA3, and dentate gyrus (DG). White square indicates the region from which pyramidal neurons were selected for confocal imaging. $(B)$ Confocal image of a representative eYFPtransfected CA1 pyramidal neuron from a serum-free slice. (C) Confocal image of a representative eYFP-transfected CA1 neuron (green), filled with Alexa-594 during whole-cell recording (red). (D) Representative continuous records of spontaneous excitatory synaptic currents. (E) Action potential train (top trace) evoked by somatic current injection (bottom trace, $200 \mathrm{pA}, 0.8 \mathrm{sec})$. ( $(F)$ Higher magnification views of representative segments of apical dendrites from control serum-free (SF) and BDNF-treated slices (scale bar, $2 \mu \mathrm{m}$ ). (G) Quantification of spine density, expressed per $10 \mu \mathrm{m}$ of apical dendrite. (\#) $P<0.001$, Student $t$ test, $t=4.615, n=10-13$.

$\mu \mathrm{m}, 13$ cells from 12 slices; $P<0.001$; Fig. 1F,G). In all of our studies, we used serum-free medium as the control condition to avoid the confounding effects of unknown amounts of hormones and growth factors potentially present in horse serum (Tyler and Pozzo-Miller 2001, 2003). The spine density in apical dendrites of eYFP-transfected CA1 pyramidal neurons obtained in the present studies is in good agreement with those we observed in Alexa-594 filled neurons (Tyler and Pozzo-Miller 2001, 2003).

\section{ERK Is Necessary for BDNF-Induced Increase in Spine Density}

Because BDNF activation of TrkB receptors leads to stimulation of the ERK (MAPK)-signaling pathway (for review, see Segal and Greenberg 1996), we tested whether this cascade is responsible for BDNF's effects on spine density. The MEK (ERK kinase) inhibitors PD98059 and U0126 (25 $\mu$ M; Alessi et al. 1995; Favata et al. 1998) completely prevented the BDNF-induced increase in spine density (BDNF + PD98059 $25 \mu \mathrm{M}=6.24 \pm 1.42$ spines $/ 10$ $\mu \mathrm{m}$, seven cells from four slices; and BDNF + U0126 25 $\mu \mathrm{M}=7.30 \pm 0.76$ spines $/ 10 \mu \mathrm{m}, 13$ cells from nine slices; both vs. $\mathrm{BDNF}=11.17 \pm 0.93$ spines $/ 10 \mu \mathrm{m}, 10$ cells from seven slices $P<0.05$; Fig. 2). This effect was dose dependent, as lower concentrations of the same inhibitors $(10 \mu \mathrm{M})$ did not prevent BDNF-induced increase in spine density (BDNF + PD98059 10 $\mu \mathrm{M}=10.32 \pm 2.19$ spines $/ 10 \mu \mathrm{m}$, five cells from three slices; $\mathrm{BDNF}+\mathrm{U} 012610 \mu \mathrm{M}=9.30 \pm 1.42$ spines $/ 10 \mu \mathrm{m}$, seven cells from three slices; $P>0.05$ vs. BDNF; Fig. 2). Treatment with PD98059 or U0126 alone in serum-free medium $(25 \mu \mathrm{M})$ did not affect spine density compared with controls (serumfree $=6.13 \pm 0.62$ spines $/ 10 \mu \mathrm{m}, 13$ cells from 12 slices, vs. PD98059 = $6.33 \pm 0.65$ spines $/ 10 \mu \mathrm{m}, 11$ cells from five slices; and vs. U0126 $=7.41 \pm 1.61$ spines $/ 10 \mu \mathrm{m}$, six cells from five slices, $P>0.05$ ). These data demonstrate that ERK signaling is necessary for BDNF to increase spine density, whereas the basal levels of ERK activity in serum-free slices do not affect spine density.

To independently confirm that the concentrations of MEK inhibitors used in the previous experiments effectively blocked ERK1/2 activation in our slice cultures, we measured the phosphorylation levels of ERK1 and ERK2 by immunoblotting of dually phosphorylated kinases (P-ERK1 and P-ERK2). Treatment of hippocampal slice cultures with BDNF (250 ng/mL, $24 \mathrm{~h})$ increased the levels of P-ERK1 and P-ERK2 compared with serumfree controls (Fig. 2C), as observed in acute hippocampal slices (Gottschalk et al. 1999). However, preincubation with PD98059 or U0126 $(25 \mu \mathrm{M})$ caused a significant reduction in P-ERK1 and P-ERK2 compared with the BDNF-treated group (Fig. 2C), confirming that BDNF activates the ERK1/2-signaling pathway in hippocampal slice cultures. No differences were observed between serum-free controls and BDNF-treated cultures when the immunoblots were stripped and reprobed using antibodies that recognize ERK1 and ERK2 independently of their phosphorylation state (Total ERK1 and ERK2), indicating that there were no effects on total protein expression, and that the same amount of protein was loaded in each lane (Fig. 2 C).

\section{BDNF Has Minor and Localized Effects on Dendritic Length in CA1 Pyramidal Neurons}

Neurotrophins increase dendritic complexity in cortical pyramidal neurons (for review, see McAllister et al. 1999). Despite its well-documented effects on synaptic transmission and plasticity in the hippocampus (for review, see Poo 2001; Tyler et al. 2002a,b), the possibility that BDNF also modulates dendritic complexity in hippocampal CA1 pyramidal neurons had not been thoroughly tested until recently (Danzer et al. 2002). To this aim, we performed a three-dimensional analysis of dendritic complexity from $z$-stacks of confocal optical sections of eYFPexpressing CA1 pyramidal neurons (Fig. 3A-D). No differences were found in the total dendritic length (Fig. 3E,F; $P>0.05$ ), or in the number of total dendritic branch points (nodes) of both basal 


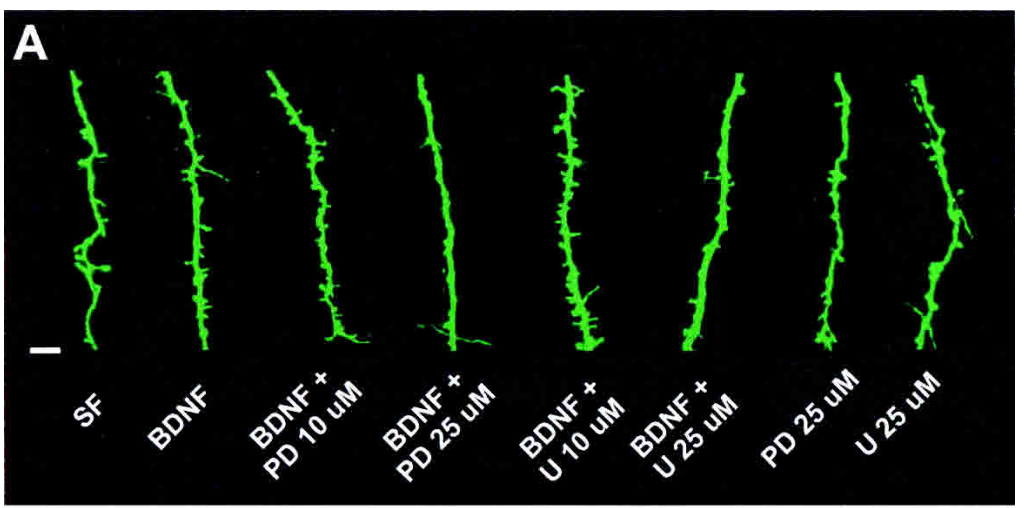

B

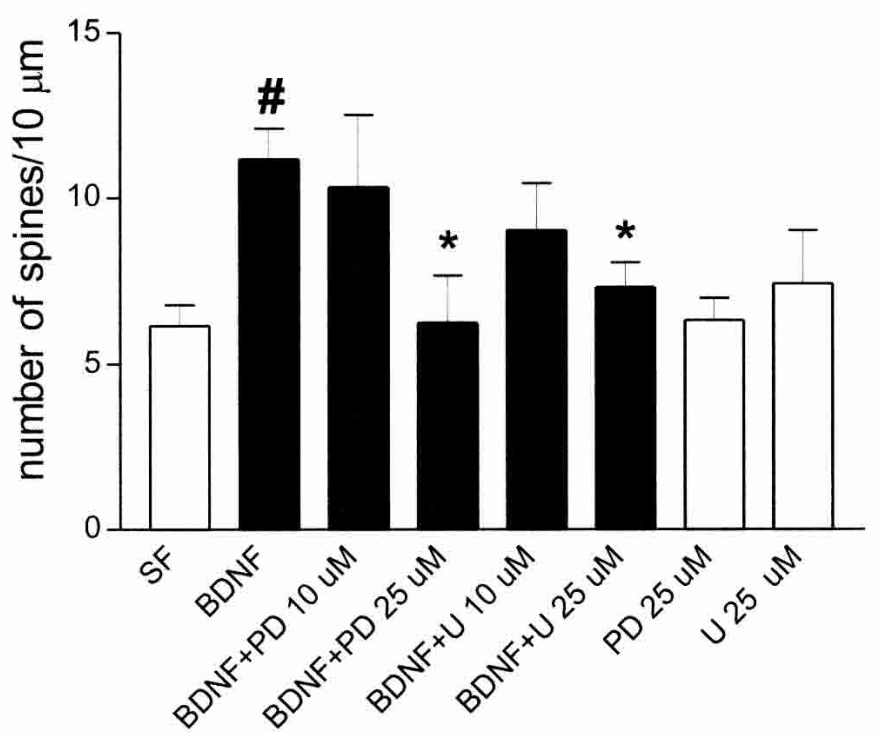

C

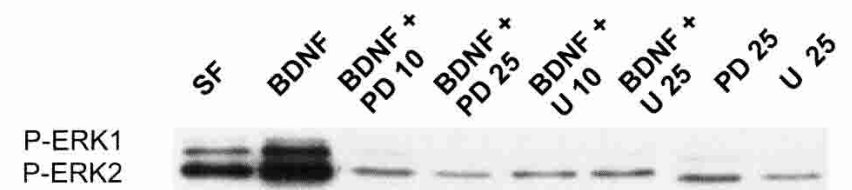

Total ERK1

Total ERK2

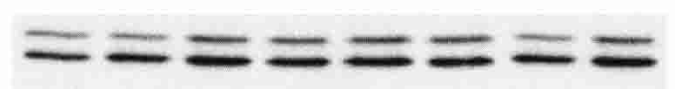

Figure 2 ERK activity is necessary for BDNF to increase spine density in CA1 pyramidal neurons. (A) High magnification views of representative segments of apical dendrites (scale bar, $2 \mu \mathrm{m}$ ). Images (left to right) are as follows: serum-free (SF); BDNF; BDNF + PD98059 at $10 \mu \mathrm{M}$ (BDNF + PD $10 \mu \mathrm{M}) ; \mathrm{BDNF}+$ PD98059 at $25 \mu \mathrm{M}(\mathrm{BDNF}+\mathrm{PD} 25 \mu \mathrm{M}) ; \mathrm{BDNF}+\mathrm{U} 0126$ at $10 \mu \mathrm{M}(\mathrm{BDNF}+\mathrm{U} 10$ $\mu \mathrm{M}) ; \mathrm{BDNF}+\mathrm{U} 0126$ at $25 \mu \mathrm{M}(\mathrm{BDNF}+\mathrm{U} 25 \mu \mathrm{M}) ;$ PD98059 at $25 \mu \mathrm{M}$ alone (PD $25 \mu \mathrm{M}) ;$ and $\mathrm{U} 0126$ at $25 \mu \mathrm{M}$ alone $(\mathrm{U} 25 \mu \mathrm{M})$. (B) Quantification of spine density, expressed per $10 \mu \mathrm{m}$ of apical dendrite. (\#) $P<0.01$ vs. SF group; $\left(^{*}\right) P<0.05$ vs. BDNF-treated group; ANOVA followed by Newman Keul test, $F(7,64)=3.475 ; n=5-13$. (C) Representative Western blots using antiphosphorylated ERK1 and ERK2 (P-ERK1 and P-ERK2) and anti-ERK1 and ERK2 (Total ERK1 and Total ERK2) antibodies in whole homogenates of hippocampal slice cultures. Lanes (left to right) are as follows: serum-free (SF); BDNF; BDNF + PD98059 at $10 \mu \mathrm{M}$ (BDNF + PD $10 \mu \mathrm{M}) ;$ BDNF + PD98059 at $25 \mu \mathrm{M}(\mathrm{BDNF}+\mathrm{PD} 25 \mu \mathrm{M}) ; \mathrm{BDNF}+\mathrm{U} 0126$ at $10 \mu \mathrm{M}(\mathrm{BDNF}+\mathrm{U} 10 \mu \mathrm{M}) ; \mathrm{BDNF}+\mathrm{U} 0126$ at $25 \mu \mathrm{M}(\mathrm{BDNF}+\mathrm{U} 25 \mu \mathrm{M}) ; \mathrm{PD} 98059$ at $25 \mu \mathrm{M}$ alone (PD $25 \mu \mathrm{M})$; and U0126 at $25 \mu \mathrm{M}$ alone (U $25 \mu \mathrm{M})$.

and apical dendrites (Fig. 3G,H; P>0.05) between BDNF (250 $\mathrm{ng} / \mathrm{mL}$ for $24 \mathrm{~h}$ ) and serum-free control slices. Analyzing these variables as a function of distance from the somata revealed a trend of an increase in the total length of apical dendrites in
BDNF-treated slices, statistically significant $(P<0.05)$ only between 240 and $260 \mu \mathrm{m}$, corresponding to stratum radiatum, in which CA3 axons form synapses with CA1 dendritic spines (serum free $=57.41 \pm$ $23.25 \mu \mathrm{m}$, nine cells from nine slices, vs. $\mathrm{BDNF}=157.1 \pm 36.34 \mu \mathrm{m}$, seven cells from seven slices, Student $t$ test, $P=0.03$; Fig. 4). No differences were found in the total length of basal dendrites, nor in the total number of branch points of basal and apical dendrites at any distance from the somata (all $P>0.05$ ). These observations suggest that BDNF has a rather small and quite spatially localized effects on dendritic length in CA1 pyramidal neurons, in marked contrast to its profound effects on dendritic complexity, including total length and branching, in cortical pyramidal neurons (McAllister et al. 1995) and dentate granule cells (Danzer et al. 2002; Tolwani et al. 2002).

\section{DISCUSSION}

We have shown previously that BDNF activation of its TrkB receptor increases spine density in apical dendrites of hippocampal CA1 pyramidal neurons (Tyler and PozzoMiller 2001, 2003). Here, we confirm and extend those findings, demonstrating that ERK activation is necessary for BDNF to induce spine growth in CA1 pyramidal neurons. In addition, we show that BDNF has rather small and localized effects on dendritic length in CA1 neurons, in contrast to its profound effects on dendritic complexity in cortical pyramidal neurons (for review, see McAllister et al. 1999). These results underscore the differences in the modulation of dendritic structure by BDNF between hippocampal versus cortical pyramidal neurons. Overexpression of BDNF in cortical pyramidal neurons elicited a destabilization of dendritic spines, leading to a reduction of their density (Horch et al. 1999), although a focal source from BDNF-overexpressing neurons did not alter the local density of dendritic protrusions on neighboring untransfected neurons (Horch and Katz 2002). On the other hand, BDNF increases spine density in hippocampal CA1 pyramidal neurons (Tyler and Pozzo-Miller 2001, 2003; Figs. 1 and 2). In addition, BDNF has localized effects on dendritic length, but not on branching of apical dendrites of CA1 neurons (Figs. 3 and 4), as opposed to the widespread increase of dendritic length and branching in cortical pyramidal neurons (McAllister et al. 1995). Consistent with this view, Danzer et al. (2002) showed recently that the effects of BDNF in the hippocampus are cell-type specific-BDNF increased dendritic complexity in dentate granule cells, without affecting CA3 or CA1 pyramidal neuron dendrites. Taken together, these observations clearly indicate that BDNF modulates dendritic structure and spine density in a cell-typespecific manner, and demonstrate the need for caution when 

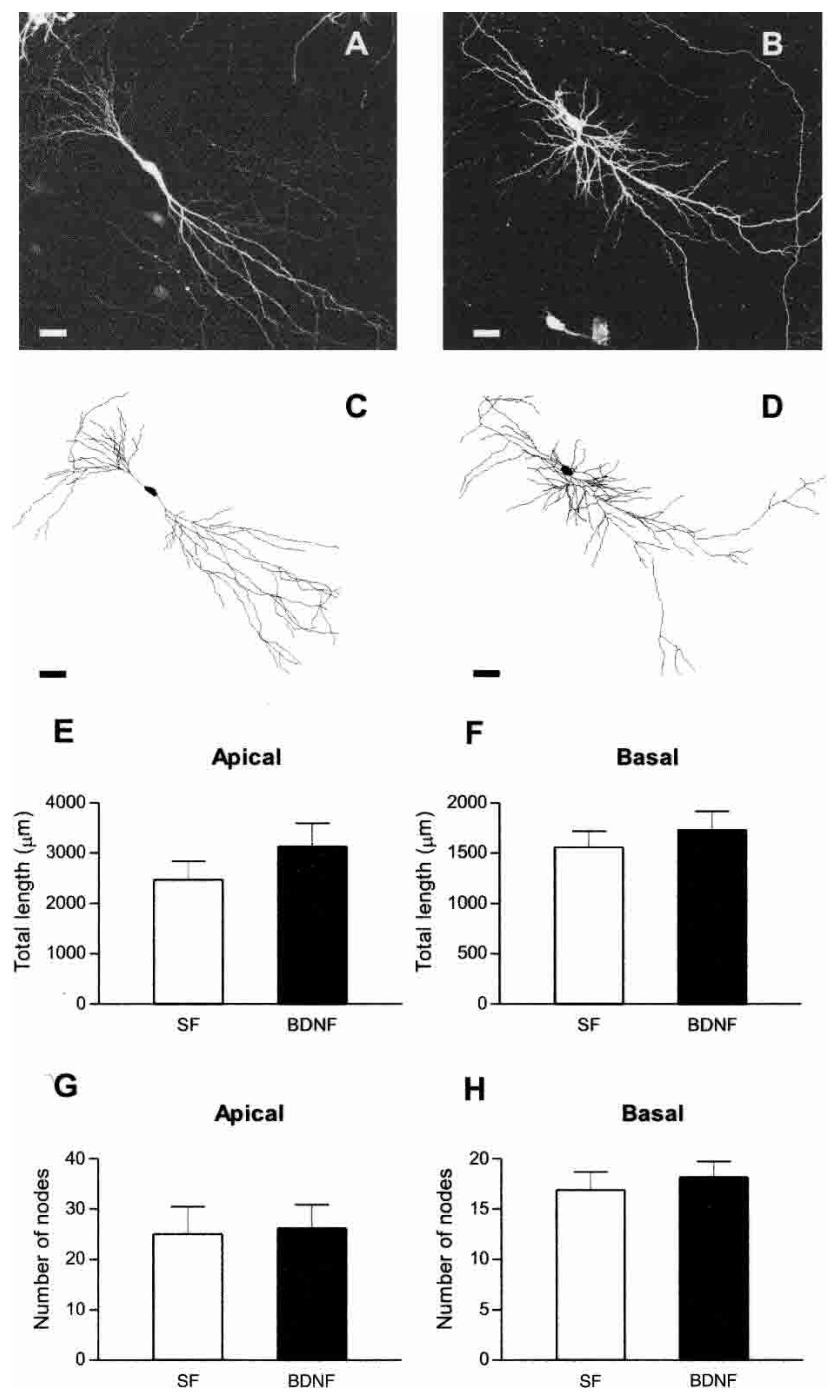

Figure 3 BDNF does not affect the length or branching of either apica or basal dendrites of CA1 pyramidal neurons. Representative low magnification views of eYFP-transfected CA1 neurons, and full tracings from serum-free $(A, C)$, and BDNF-treated slices $(B, D$; scale bar, $50 \mu \mathrm{m})$. Total length of apical $(E)$ and basal $(F)$ dendrites, and total number of apical $(G)$ and basal $(H)$ branch points. $P<0.05$ in all cases; Student's $t$ test, $n=7-9$.

generalizing the actions of neurotrophins on dendritic morphology.

In the present and all of our previous studies of BDNF's actions using organotypic cultures of hippocampal slices (Tartaglia et al 2001; Tyler and Pozzo-Miller 2001, 2003; McCutchen et al. 2002), we used serum-free medium as the control condition to avoid the confounding effects of unknown amounts of hormones and growth factors potentially present in the horse serum. This rationale stems from the observation that BDNF did not increase spine density in CA1 pyramidal neurons when applied to slice cultures maintained in horse serum containing medium (L. Pozzo-Miller, unpubl.). This is in contrast to the effects of estrogen, which increased spine density in CA1 neurons maintained in serum containing medium (Pozzo-Miller et al. 1999). Thus, it appears as though the unknown quantities of growth factors and hormones present in the horse serum-or their effects on BDNF expression and/or release from cells within the cultured slices-may differentially affect the modulation of spine density by estrogen versus BDNF, potentially due to different intracellular signaling cascades. In addition, the spine density in CA1 neurons of slices maintained in medium containing $20 \%$ horse serum (the standard protocol; Gähwiler 1981; Yamamoto et al. 1989; Stoppini et al. 1991) are comparable with those observed in slices exposed to BDNF in serum-free conditions $(11.17 \pm 0.36$ spines $/ 10 \mu \mathrm{m}$ in medium vs. $9.46 \pm 0.22$ spines $/ 10 \mu \mathrm{m}$ in serumfree plus BDNF; data from Tyler and Pozzo-Miller 2003). On the other hand, endogenous BDNF signaling seems to modulate spine density in slices maintained in serum containing medium, as exposure to function blocking anti-BDNF antibodies $(50 \mu \mathrm{g} /$ $\mathrm{mL})$, or the endogenous BDNF scavenger TrkB-IgG $(20 \mu \mathrm{g} / \mathrm{mL}$; Shelton et al. 1995), reduced spine density in CA1 pyramidal neurons by $52 \%$ and $51 \%$ compared with neurons of slices kept in serum containing medium, respectively (L. Pozzo-Miller, in prep.). Taken together, these results underscore the importance of the culture medium composition in those studies of neurotrophin and hormone actions on dendritic and spine structure using in vitro cultured preparations.

Regarding the specific role of ERK1/2 in BDNF-induced spinogenesis in CA1 neurons, it has been reported that PD098059 and U0126, two widely used MEK inhibitors, also inhibit ERK5 in COS7 cells (Kamakura et al. 1999). Because BDNF/ TrkB signaling could also activate ERK5 in cortical and dorsal root ganglion (DRG) neurons (Cavanaugh et al. 2001; Watson et al. 2001), we cannot presently rule out the contribution of this kinase to BDNF-induced spine formation in hippocampal slice cultures. However, a recent study indicated that ERK5 is highly expressed in the mammalian brain early during development, gradually declining as the brain matures (Liu et al. 2003). Together with its role in neuronal survival (Liu et al. 2003), these observations suggest that the role of ERK5 could be more prominent early during development, with less involvement in postnatal phenomena in established neuronal populations, such as those studied here.

Dendritic spines are the sites of diverse synaptic plasticity events, ranging from changes in synaptic strength (for review, see Sorra and Harris 2000; Yuste and Bonhoeffer 2001) to experiencedependent plasticity in vivo (for review, see Zito and Svovoda 2002). We have shown recently that BDNF signaling via ERK1/2 in the CA1 region is required for a hippocampal-dependent, onetrial avoidance-learning task in rats (Alonso et al. 2002a). Considering that BDNF activation of ERK1/2 also induces long-term potentiation in the dentate gyrus in vivo (Ying et al. 2002), the present results on dendritic spine density strongly suggest that $\mathrm{BDNF} / \mathrm{TrkB}$ signaling is converging on the ERK1/2 cascade to induce enduring changes at the behavioral, physiological, and morphological levels (for review, see Tyler et al. 2002a).

\section{MATERIAL AND METHODS}

\section{Organotypic Slice Cultures}

Hippocampal slices from postnatal-days 7 to 10 (P7-P10) Sprague-Dawley rats were cultured as described previously (Tyler and Pozzo-Miller 2001, 2003). The confounding effects from unwanted factors in the sera were eliminated by using a fully defined, serum-free medium in all control groups (Neurocellular-II, Biofluids; plus B-27 supplement; Invitrogen). Antibiotics, antimycotics, or proliferation inhibitors were never included in the culture medium.

\section{Particle-Mediated Gene Transfer}

Slices were transfected at $7 \mathrm{~d}$ in vitro (div), after $24 \mathrm{~h}$ in serumfree medium. Plasmid DNA coding for enhanced yellow fluorescent protein (eYFP; Clontech; a gift from Dr. C. Garner (Stanford University) was introduced by biolistic transfection using a gene gun (Helios, Bio-Rad) following the manufacturer's protocols. DNA was precipitated onto colloidal gold $(1.6 \mu \mathrm{m})$ at a ratio of 2 


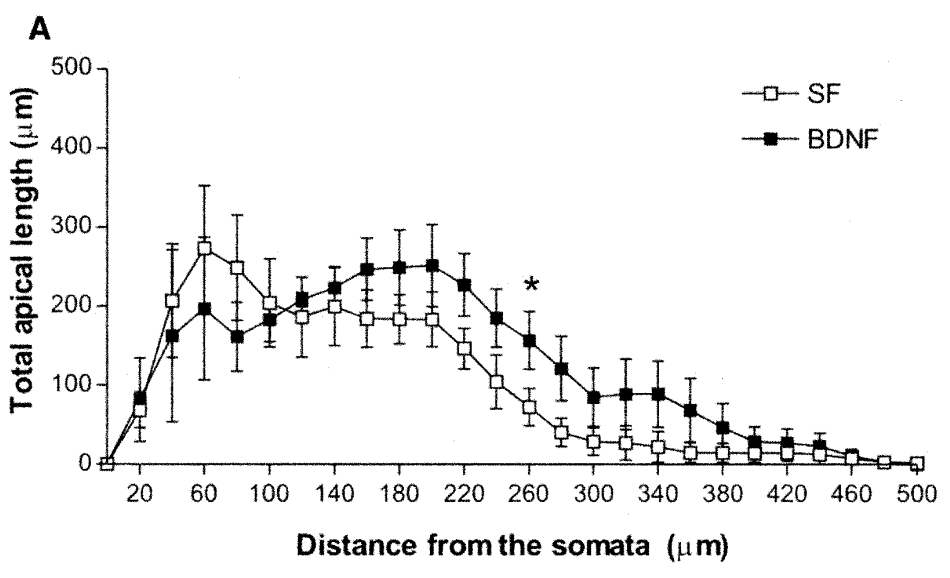

B

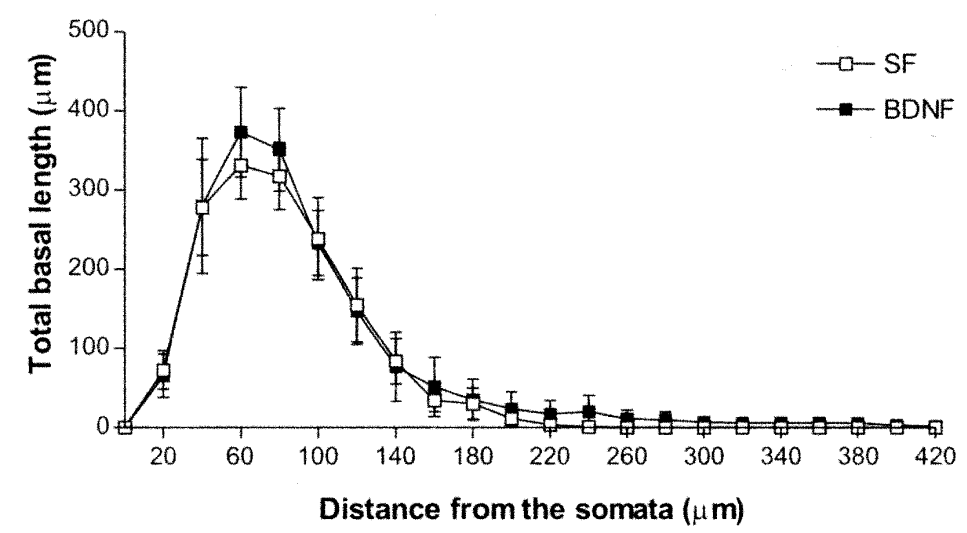

Figure 4 BDNF has small and localized effects on apical, not basal, dendritic length in CA1 pyramidal neurons. Total length of apical $(A)$ and basal $(B)$ dendrites as a function of distance from the soma. $\left(^{*}\right) P<0.05$; Student's $t$ test, $n=7-9$.

$\mu \mathrm{g}$ DNA to $1 \mathrm{mg}$ gold, and then coated onto Tefzel tubing using polyvinypyrrolidine $(0.06 \mathrm{mg} / \mathrm{mL})$. Slices were bombarded in the culture plates (He pressure: $100 \mathrm{psi}$; distance: $\sim 15 \mathrm{~mm}$ ). Culture medium was changed $24 \mathrm{~h}$ after transfection, and every $2 \mathrm{~d}$ thereafter.

\section{Kinase Inhibitor Treatments}

Slices were assigned randomly to the following groups: (1) serumfree medium control; (2) BDNF ( $250 \mathrm{ng} / \mathrm{mL}$; provided by Amgen) in serum-free medium; (3) BDNF preceded, and in conjunction with PD98059 (10 or $25 \mu \mathrm{M}$; Promega); (4) BDNF preceded, and in conjunction with U0126 (10 or $25 \mu \mathrm{M}$; Cell Signaling); (5) PD98059 $(25 \mu \mathrm{M})$ alone in serum-free medium; and (6) U0126 $(25 \mu \mathrm{M})$ alone in serum-free medium. The ERK1/2 inhibitors, PD98059 and U0126, were dissolved in DMSO (1:1000 final dilution); vehicle controls were performed by treating slice cultures with a 1:1000 dilution of DMSO in culture medium. The inhibitors alone were added 30 min before the application of BDNF plus inhibitors. A total of $50 \mu \mathrm{L}$ of medium was placed onto the slices to facilitate entry of the compounds, followed by fullmedium exchange $(\sim 1 \mathrm{~mL}$ per well). All treatments lasted $24 \mathrm{~h}$, beginning 3-4 d after transfection. The concentration of BDNF used in the present studies $(250 \mathrm{ng} / \mathrm{mL})$ was chosen on the basis of previous reports, including our own, demonstrating robust effects on dendritic morphology in brain slices (McAllister et al, 1995; Horch et al. 1999; Tyler and Pozzo-Miller 2001, 2003).

\section{Slice Culture Fixation and Selection of CAl Pyramidal Neurons}

Slices were fixed by immersion in $4 \%$ paraformaldehyde in 100 $\mathrm{mM}$ phosphate buffer $\left(\mathrm{PB} ; \sim 36^{\circ} \mathrm{C}\right)$ for $40 \mathrm{~min}$ at room tempera- ture (RT), followed by $\mathrm{PB}$ saline (PBS) washes $(4 \times, 15 \mathrm{~min})$, trimming of the filter membrane around the slices, and mounting on glass slides with Vectashield (Vector Laboratories). Only small numbers of pyramidal neurons happened to be transfected per slice, usually none to three in each slice, making it easy to distinguish the entire dendritic arborization of individual neurons. Hippocampal cell layers and subregions were identified by NeuN immunofluorescence following conventional protocols, including blocking and permeabilization (horse serum, bovine serum albumin, and Triton-X), incubation with anti-NeuN primary antibodies $(1 / 100,24 \mathrm{~h}$ at RT; Chemicon), secondary antibodies (1/200; biotinconjugated anti-mouse, Jackson Immunoresearch), streptavidin-conjugated Texas Red $(10 \mu \mathrm{g} / \mathrm{mL}, 30 \mathrm{~min}$ at RT; Vector Laboratories), and mounting with Vectashield. CA1 pyramidal neurons were selected strictly for analysis only if their somata lay within CA1 stratum pyramidale and were smaller than that of CA3 pyramidal neurons, and their characteristic apical and basal dendrites were fully recognizable. Lastly, selected CA1 neurons had to display eYFP fluorescence throughout their dendritic tree, and be absent of degenerative changes (i.e., dendritic blebbling).

\section{Confocal Imaging}

Low-magnification views of entire neurons, and high-resolution images of distal secondary and tertiary branches of apical dendrites were acquired with an Olympus Fluoview FV-300 laser-scanning confocal microscope (Olympus Fluoview) using dry $20 \times$ (NA 0.5) and oil immersion $100 \times($ NA 1.4) objectives (Olympus PlanApo), respectively. eYFP fluorescence was excited using an argon laser $(488 \mathrm{~nm})$ and detected using standard FITC filters, whereas Texas Redconjugated antibodies and Alexa-594 were imaged using a krypton laser $(647 \mathrm{~nm})$ and standard Texas Red filters. Series of optical sections in the $z$-axis were acquired at 0.5 or $0.1 \mu \mathrm{m}$ intervals for entire neurons and distal dendrites, respectively.

\section{Analysis of Spine Density}

Dendritic spines were identified as small protrusions extending $\leq 3.0 \mu \mathrm{m}$ from their parent dendrite, and counted off-line using ImageJ (National Institutes of Health). Care was taken to ensure that each spine was counted only once by following its course through the stack of $z$-sections. Only spines appearing continuous with their parent dendrites were used for quantitative analyses. Spine density was calculated by quantifying the number of spines per unit length of dendrite, and normalized to $10 \mu \mathrm{m}$ of dendritic length. The total dendritic length used for spine densitometry was as follows: serum free $=1045.92 \mu \mathrm{m}$; $\mathrm{BDNF}=1024.59 \mu \mathrm{m} ; \mathrm{BDNF}+\mathrm{PD} 9805910 \mu \mathrm{M}=513.91$; $\mathrm{BDNF}+\mathrm{PD} 9805925 \mu \mathrm{M}=667.57 \mu \mathrm{m} ; \mathrm{BDNF}+\mathrm{U} 012610$ $\mu \mathrm{M}=829.61 \mu \mathrm{m} ; \mathrm{BDNF}+\mathrm{U} 012625 \mu \mathrm{M}=1230.32 \mu \mathrm{m} ;$ PD98059 $25 \mu \mathrm{M}=1075.94 \mu \mathrm{m}$; and U0126 $25 \mu \mathrm{M}=511.34 \mu \mathrm{m}$. Microscope calibrations were performed using 0.2 and $1 \mu \mathrm{m}$ latex fluorescent beads (Molecular Probes).

\section{Dendritic Complexity Analysis}

Neurons were traced in three dimensions from the $z$-stacks using Neurolucida (MicroBrigthField). The intersections of traced dendrites with a series of concentric spheres starting at the soma and spaced at $20-\mu \mathrm{m}$ intervals were used as a measure of dendritic complexity. The total dendritic length and number of dendritic

\section{Learning \& Memory


branch points (nodes) were calculated and used for statistical comparisons.

\section{Electrophysiological Recordings}

Whole-cell recordings were performed from visually identified eYFP-transfected CA1 pyramidal neurons in 8-10 div slice cultures using simultaneous IR-DIC and epifluorescence microscopy (Pozzo-Miller et al. 1999). eYFP fluorescence (standard FITC filters), and sometimes a gold particle $(1.6 \mu \mathrm{m})$ were used as visual guides for patch-clamping a transfected CA1 neuron. The recorded neuron was unambiguously identified by including Alexa-594 (Molecular Probes) in the patch pipette $(132 \mu \mathrm{M})$, and using standard Texas Red filters. Following whole-cell recording, the electrode was gently removed and the slice fixed for 2-channel confocal microscopy.

\section{Immunoblot Assays}

Three slices per group were pooled and homogenized in icechilled lysis buffer. Samples ( $5 \mu \mathrm{g}$ of protein) were subjected to SDS-PAGE (10\% gels), and immunoblots were performed with anti-ERK1 and 2 (1:1000) and anti-phosphorylated ERK1 and ERK2 (1:1000; both from New England Biolabs), as described previously (Alonso et al. 2002a,b).

\section{Statistical Analysis}

All measurements were performed in a blind fashion. Data were analyzed statistically using unpaired Student's $t$ tests, or analysis of variance (ANOVA), followed by Newman-Keuls as post-hoc test, all using Prism (GraphPad). $P<0.05$ was considered significant. Data are presented as mean \pm standard error of the mean.

\section{ACKNOWLEDGMENTS}

This work was supported by Fundación Antorchas of Argentina (to M.A.), and NIH grants RO1-NS40593 (to L.P.-M.), PO1HD38760, and P30-HD38985. We thank C. Garner (Stanford University) for the eYFP plasmid, S. Fenster and T. Whitworth (UAB-MRRC) for help with the cDNA constructs, P. Pomata (UAB, USA, and UBA, Argentina) for whole-cell recordings from eYFPtransfected neurons, R. Andrade (Wayne State University) for introduction to biolistic transfections, W. Tyler (Harvard University) for discussions, T. Inoue (Tokyo University, Japan) for electrophysiology acquisition software, and the High Resolution Imaging Facility (UAB) for the use of the confocal microscope. We also thank Amgen for the generous supply of BDNF.

The publication costs of this article were defrayed in part by payment of page charges. This article must therefore be hereby marked "advertisement" in accordance with 18 USC section 1734 solely to indicate this fact.

\section{REFERENCES}

Alessi, D.R., Cuenda, A., Cohen, P., Dudley, D.T., and Saltiel, A.R. 1995. PD098059 is a specific inhibitor of the activation of mitogen-activated protein kinase kinase in vitro and in vivo. J. Biol. Chem. 270: 27489-27494.

Alonso, M., Vianna, M.R.M., Depino, A.M., Mello e Souza, T., Pereira, P., Szapiro, G., Viola, H., Pitossi, F., Izquierdo, I., and Medina, J.H. 2002a. BNDF-triggered events in the rat hippocampus are required for both short- and long-term memory formation. Hippocampus 12: $551-560$.

Alonso, M., Vianna, M.R.M., Izquierdo, I., and Medina, J.H. 2002b. Signaling mechanisms mediating BDNF modulation of memory formation in vivo in the hippocampus. Cell. Mol. Neurobiol. 22: $647-658$.

Blanquet, P.R. 2000. Identification of two persistently activated neurotrophin-regulated pathways in rat hippocampus. Neuroscience 95: 705-719.

Cavanaugh, J.E., Ham, J., Hetman, M., Poser, S., Yang, C., and Xia, Z. 2001, Differential regulation of mitogen-activated protein kinases ERK1/2 and ERK5 by neurotrophins, neuronal activity, and cAMP in neurons. J. Neurosci. 21: 434-443.

Danzer, S.C., Crooks, K.R.C., Lo, D.C., and McNamara, J.O. 2002. Increased expression of brain-derived neurotrophic factor induces formation of basal dendrites and axonal branching in dentate granule cells in hippocampal explants cultures. J. Neurosci. 22: $9754-9763$.

Favata, M.F., Horiuchi, K.Y., Manos, E.J., Daulerio, A.J., Stradley, D.A., Feeser, W.S., Van Dyk, D.E., Pitts, W.J., Earl, R.A., Hobbs, F., et al. 1998. Identification of a novel inhibitor of mitogen-activated protein kinase kinase. J. Biol. Chem. 273: 18623-18632.

Finkbeiner, S., Tavazoie, S., Maloratsky, A., Jacobs, K., Harris, K., and Greenberg, M. 1997. CREB: A major mediator of neuronal neurotrophin responses. Neuron 19: 1031-1047.

Gähwiler, B.H. 1981. Organotypic monolayer cultures of nervous tissue. J. Neurosci. Meth. 4: 329-342.

Gottschalk, W.A., Jiang, H., Tartaglia, N., Feng, L., Figurov, A., and Lu, B. 1999. Signaling mechanisms mediating BDNF modulation of synaptic plasticity in the hippocampus. Learn Mem. 6: 243-256.

Horch, H.W. and Katz, L.C. 2002. BDNF release from single cell elicits local dendritic growth in nearby neurons. Nat. Neurosci. 11: $1177-1184$.

Horch, H.W., Kruttgen, A., Protbury, S.D., and Katz, L.C. 1999. Destabilization of cortical dendrites and spines by BDNF. Neuron 23: 353-364.

Kamakura, S., Moriguchi, T., and Nishida, E. 1999. Activation of the protein kinase ERK5/BMK1 by receptor tyrosine kinases. J. Biol. Chem. 274: 26563-26571.

Liu, L., Cavanaugh, J.E., Wang, Y., Sakagami, H., Mao, Z., and Xia, Z 2003. ERK5 activation of MEF2-mediated gene expression plays a critical role in BDNF-promoted survival of developing but not mature cortical neurons. Proc. Natl. Acad. Sci. 100: 8532-8537.

Lo, D.C., McAllister, A.K., and Katz, L.C. 1994. Neuronal transfection in brain slices using particle-mediated gene transfer. Neuron 13: $1263-1268$.

Lonze, B.E. and Ginty, D.D. 2002. Function and regulation of CREB family transcription factors in the nervous system. Neuron 35: 605-623.

McAllister, A.K., Katz, L.C., and Lo, D.C. 1995. Neurotrophins regulate dendritic growth in developing visual cortex. Neuron 15: 791-803.

. 1999. Neurotrophins and synaptic plasticity. Annu. Rev. Neurosci. 22: 295-318.

McCutchen, M.E., Bramham, C.R., and Pozzo-Miller, L.D. 2002. Modulation of neuronal calcium signaling by neurotrophic factors. Int. J. Dev. Neurosci. 20: 199-207.

Mertz, K., Koscheck, T., and Schilling, K. 2000. Brain-derived neurotrophic factor modulates dendritic morphology of cerebellar basket and stellate cells: An in vitro study. Neuroscience 97: 303-310.

Pizzorusso, T., Ratto, G.M., Putignano, E., and Maffei, L. 2000. Brain-derived neurotrophic factor causes cAMP response element-binding protein phosphorylation in absence of calcium increase in slices and cultured neurons from rat visual cortex. $J$. Neurosci. 20: 2809-2816.

Poo, M. 2001. Neurotrophins as synaptic modulators. Nat. Rev. Neurosci. 2: $24-32$.

Pozzo-Miller, L.D., Inoue, T., and Murphy, D.D. 1999. Estradiol increases spine density and NMDA-dependent $\mathrm{Ca}^{2+}$ transients in spines of CA1 pyramidal neurons from hippocampal slices. J. Neurophysiol. 81: $1404-1411$.

Schwartz, P.M., Borghesani, P.R., Levy, R.L., Pomeroy, S.L., and Segal, R.A. 1997. Abnormal cerebellar development and foliation in BDNF $-/-$ mice reveals a role for neurotrophins in CNS patterning. Neuron 19: 269-281.

Segal, R.A. and Greenberg, M.E. 1996. Intracellular signaling pathways activated by neurotrophic factor. Annu. Rev. Neurosci. 19: 463-489.

Shelton, D.L., Sutherland, J., Gripp, J., Camerato, T., Armanini, M.P. Phillips, H.S., Carroll, K., Spencer, S.D., and Levinson, A.D. 1995. Human trks: Molecular cloning, tissue distribution, and expression of extracellular domain immunoadhesins. J. Neurosci. 15: 477-491.

Shimada, A., Mason, C.A., and Morrison, M.E. 1998. TrkB signaling modulates spine density and morphology independent of dendrite structure in cultured neonatal Purkinje cells. J. Neurosci. 18: $8559-8570$.

Sorra, K.E. and Harris, K.M. 2000. Overview on the structure, composition, function, development, and plasticity of hippocampal dendritic spines. Hippocampus 10: 501-511.

Stoppini, L., Buchs, P.A., and Muller, D. 1991. A simple method for organotypic cultures of nervous tissue. J. Neurosci. Meth. 37: $173-182$.

Tartaglia, N., Du, J., Tyler, W.J., Neale, E., Pozzo-Miller, L., and Lu, B. 2001. Protein synthesis-dependent and -independent regulation of hippocampal synapses by brain-derived neurotrophic factor. J. Biol. Chem. 276: 37585-37593.

Tolwani, R.J., Buckmaster, P.S., Varma, S., Cosgaya, J.M., Wu, Y., Suri, C., and Shooter, E.M. 2002. BDNF overexpression increases dendrite complexity in hippocampal dentate gyrus. Neuroscience 3: 795-805.

Tyler, W.J. and Pozzo-Miller, L.D. 2001. BDNF enhances quantal 


\section{Alonso et al.}

neurotransmitter release and increases the number of docked vesicles at the active zones of hippocampal excitatory synapses. J. Neurosci.

21: $4249-4258$.

2003. Miniature synaptic transmission and BDNF modulate dendritic spine growth and form in rat CA1 neurones. J. Physiol. 553: 497-509.

Tyler, W.J., Alonso, M., Bramham, C.R., and Pozzo-Miller, L.D. 2002a. From acquisition to consolidation: On the role of brain-derived neurotrophic factor signaling in hippocampal-dependent learning. Learn. Mem. 9: 224-237.

Tyler, W.J., Perrett, S., and Pozzo-Miller, L.D. 2002b. The role of neurotrophins in neurotransmitter release. Neuroscientist 8: 524-531.

Vicario-Abejon, C., Owens, D., McKay, R., and Segal, M. 2002. Role of neurotrophins in central synapse formation and stabilization. Nat. Neurosci. Rev. 3: 965-974.

Watson, F.L., Heerssen, H.M., Bhattacharyya, A., Klesse, L., Lin, M.Z., and Segal, R. 2001. Neurotrophins use the ERK5 pathway to mediate a retrograde survival response. Nat. Neurosci. 4: 981-988.

Wu, G-Y., Deisseroth, K., and Tsien, R.W. 2001. Spaced stimuli stabilize MAPK pathway activation and its effects on dendritic morphology. Nat. Neurosci. 4: 151-158.
Yacoubian, T.A. and Lo, D.C. 2000. Truncated and full-length TrkB receptors regulate distinct modes of dendritc growth. Nat. Neurosci. 3: $342-349$.

Yamamoto, N., Kurotani, T., and Toyama, K. 1989. Neural connections between the lateral geniculate nucleus and visual cortex in vitro. Science 245: 192-194.

Ying, S.W., Futter, M., Rosenblum, K., Webber, M.J., Hunt, S.P., Bliss, T.V., and Bramham, C.R. 2002. Brain-derived neurotrophic factor induces long-term potentiation in intact adult hippocampus: Requirement for ERK activation coupled to CREB and upregulation of Arc synthesis. J. Neurosci. 22: 1532-1540.

Yuste, R. and Bonhoeffer, T. 2001. Morphological changes in dendritic spines associated with long-term synaptic plasticity. Annu. Rev. Neurosci. 24: 1071-1089.

Zito, K. and Svoboda, K. 2002. Activity-dependent synaptogenesis in the adult mammalian cortex. Neuron 35: 1015-1017.

Received July 28, 2003; accepted in revised form November 17, 2003. 


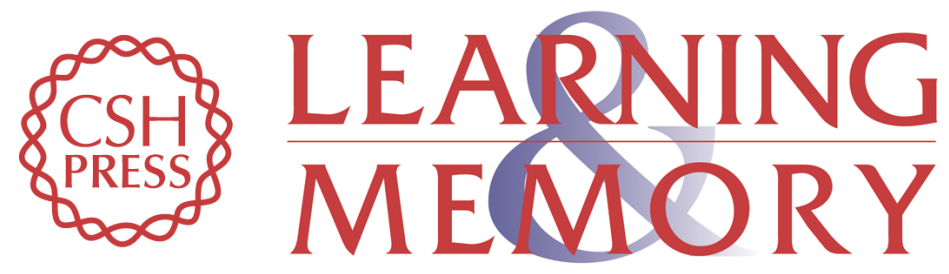

\section{ERK1/2 Activation Is Necessary for BDNF to Increase Dendritic Spine Density in Hippocampal CA1 Pyramidal Neurons}

Mariana Alonso, Jorge H. Medina and Lucas Pozzo-Miller

Learn. Mem. 2004, 11:

Access the most recent version at doi:10.1101//m.67804

References This article cites 40 articles, 15 of which can be accessed free at:

http://learnmem.cshlp.org/content/11/2/172.full.html\#ref-list-1

License

Email Alerting Receive free email alerts when new articles cite this article - sign up in the box at the top Service right corner of the article or click here. 